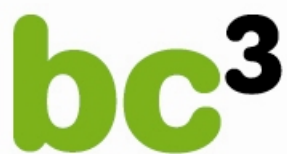

BASQUE CENTRE FOR CLIMATE CHANGE

Klima Aldaketa Ikergai

\title{
Local and Global Externalities, Environmental Policies and Growth
}

Karen Pittel and Dirk Rübbelke

October 2010

BC3 WORKING PAPER SERIES

2010-15 
The Basque Centre for Climate Change (BC3) is a Research Centre based in the Basque Country, which aims at contributing to long-term research on the causes and consequences of Climate Change in order to foster the creation of knowledge in this multidisciplinary science.

The BC3 promotes a highly-qualified team of researchers with the primary objective of achieving excellence in research, training and dissemination. The Scientific Plan of BC3 is led by the Scientific Director, Prof. Anil Markandya.

The core research avenues are:

- $\quad$ Adaptation to and the impacts of climate change

- $\quad$ Measures to mitigate the amount of climate change experienced

- $\quad$ International Dimensions of Climate Policy

- $\quad$ Developing and supporting research that informs climate policy in the Basque Country

See www.bc3research.org for further details.

The BC3 Working Paper Series is available on the internet at http://www.bc3research.org/working_papers/view.html

Enquiries (Regarding the BC3 Working Paper Series):

Roger Fouquet

Email: roger.fouquet@bc3research.org

The opinions expressed in this working paper do not necessarily reflect the position of Basque Centre for Climate Change (BC3) as a whole.

Note: If printed, please remember to print on both sides. Also, perhaps try two pages on one side. 


\title{
Local and Global Externalities, Environmental Policies and Growth
}

\author{
Karen Pittel ${ }^{* *}$ and Dirk Rübbelke ${ }^{* * *}$
}

The paper analyzes the implications of local and global pollution when two types of abatement activities can be undertaken. One type reduces solely local pollution (e.g., use of particulate matter filters) while the other mitigates global pollution as well (e.g., application of fuel saving technologies). In the framework of a 2-country endogenous growth model, the implications of different assumptions about the degree to which global externalities are internalized are analyzed. Subsequently, we derive policy rules adapted to the different scenarios. Special attention is paid to pollution, growth and optimal policy in the case of asymmetric internalization.

Keywords: economic growth, global and local externalities, government policies JEL: O4, Q53, Q54, Q58

** ifo Institute for Economic Research, Poschingerstr. 5, 81679 Munich, Germany, email: pittel@ifo.ch, and University of Munich.

*** Basque Centre for Climate Change (BC3), Gran Via, 35-2, 48009, Bilbao, Spain, email: ruebbelke@bc3research.org, and IKERBASQUE, Basque Foundation for Science, 48011, Bilbao, Spain. 


\section{Introduction}

When analyzing abatement activities that aim at combating climate change, it is mostly assumed that this abatement solely reduces the emission of $\mathrm{CO}_{2}$ or other greenhouse gases. In reality however, many activities that reduce emissions of greenhouse gases also reduce local pollution. Consequently, when discussing climate policies, not only the returns from abating global pollution but also from reducing local pollution should be considered. Equivalently, when deciding about policies to reduce local pollution, the analysis of available abatement options should take potential side effects on global pollution into account. Thus, local and global environmental policies should not be treated separately but rather in a unified framework. In this paper, we set up a model that accounts for local as well as global pollution and explicitly considers two types of abatement activities that differ with respect to their implications regarding local and global pollution mitigation. Using this approach, we can not only derive consequences of different degrees of internalization for both pollution types, but we can also characterize policies that result in an optimal abatement mix, pollution stock and growth. ${ }^{1}$

Take the reduction of $\mathrm{CO}_{2}$-emissions from transport as one example that reduces global as well as local pollutants. Decreasing fossil fuel combustion by increasing technological efficiency not only decreases the emissions of greenhouse gases like $\mathrm{CO}_{2}, \mathrm{CH}_{4}$ and $\mathrm{N}_{2} \mathrm{O}$ but also reduces emissions of, e.g., particulate matter, $\mathrm{SO}_{2}$ and $\mathrm{NO}_{x}$. Consequently, negative effects of these pollutants like health problems, acid rain, and surface corrosion are mitigated as well (see, e.g., Rübbelke 2002). Similarly, aforestation and deforestation not only enhance carbon sequestration but can also reduce soil erosion and foster bio-diversity. ${ }^{2}$ In the literature on climate change, these additional benefits which are mostly of a local nature (see, e.g., Pearce 1992, IPCC 1996) are often referred to as 'ancillary benefits', implying that the main benefit lies in the reduction of greenhouse gases. A more neutral term is 'co-benefits' (see IPCC 2001) which leaves

\footnotetext{
${ }^{1}$ In this paper, we only differentiate between global and local pollution where the latter includes all types of non-global pollution (e.g. regional).

${ }^{2}$ For specific types of additional benefits from climate policies see, e.g., Burtraw et al. (2003) regarding the mitigation of local and regional air pollution; Barker, Johnstone and O'Shea (1993) with respect to the reduction of noise, road surface damage and traffic congestion and Elbakidze and McCarl (2007) on the prevention of soil erosion and of biodiversity loss. Potential rises in employment levels, competitiveness and energy security are treated by Bovenberg (1999) and Porter (1991) and IEA (2007) respectively.
} 
undecided whether the primary target is the mitigation of global or local pollution. These co-benefits are often neglected although they are estimated to be of considerable size (see, e.g., Pearce 2000). ${ }^{3}$ Consequently, a comprehensive analysis of the costs and benefits of, e.g., the global warming problem should incorporate co-benefits from preventing greenhouse gas emissions (see also Morgenstern 1991, Plambeck, Hope and Anderson 1997).

In our paper we therefore include two types of pollution - local flow pollution and global stock pollution - as well as two types of abatement. Abatement either affects local pollution only, or local and global pollution simultaneously. The former could, for example, refer to filters that reduce the emission of particulate matter. The latter could be the aforementioned reduction of fuel combustion. Whether its main target is global or local pollution depends on the aim of the policy maker. Considering these different pollution and abatement types and their interrelations, we analyze their effects on different internalization strategies and environmental policies.

In order to include not only the intertemporal spillovers from $\mathrm{CO}_{2}$-accumulation but also their transnational nature, we consider two countries that each produces and pollutes. To keep the focus on the internalization of the pollution externalities, we employ an AK-type endogenous growth model in which no other market failures arise. We also abstract from any flows of goods or capital between countries, such that the two economies only affect each other through transnational pollution spillovers.

A look at the related literature shows that, so far, most papers that consider both - local as well as global - benefits from pollution abatement have been case studies assessing the level of ancillary benefits for individual regions or countries (e.g., Gielen and Chen 2001, Li 2006) or have been analytical models which employed static approaches neglecting dynamic implications (e.g., Pittel and Rübbelke 2008; Finus and Rübbelke 2008). ${ }^{4}$

The strand of analytical literature that deals with the dynamics of economic de-

\footnotetext{
${ }^{3}$ Regarding early climate-damage estimates, for example, Pearce (1992) argued that the consideration of co-benefits would increase Nordhaus' highest marginal-damage estimate of US\$ 66 per ton of carbon to more than US\$150.

${ }^{4}$ Furthermore, a number of studies have assessed specific co-benefits benefits of climate policies, especially in terms of public health. For surveys of the literature see, for example, Ekins (1996) and Kverndokk and Rosendahl (2000). As in our paper, most studies explore short-term, local co-benefits, only a few include long-term co-benefits at a global scale (see, e.g. Eyckmans and Bertrand 2000 and Tol 2002).
} 
velopment, and the growth-pollution nexus specifically, usually considers either flow or stock pollution but does not take potential interrelations into account (e.g., Withagen 1995, Smulders and Gradus 1996, Schou 2000, 2002). Furthermore, it is rarely distinguished between local and global pollution as most approaches assume closed economies. One exception is the paper by Bahn and Leach (2008) who consider secondary effects of climate policy due to the reduction of $\mathrm{SO}_{2}$ emissions in an overlapping generation model. Their model is, however, not analytical solvable, such that transmission channels of secondary benefits and costs are not clearly identifiable. An analytical solvable paper that considers transnational spillovers in an endogenous growth setting is Ligthart and van der Ploeg (1994). Yet, their paper focusses on renewable resources and takes neither global versus local pollution nor environmental spillovers into account. ${ }^{5}$

The remainder of the paper is organized as follows: After the introduction of the model in Section 2, we consider four different internalization scenarios that are implemented by a central planner in Section 3. These scenarios differ a) in the degree of internalization of the global externality and b) with respect to the symmetry of internalization in the two countries. In Section 4 we then consider different policy options to decentralize the planner solutions and evaluate them regarding their potential to achieve the intertemporal global welfare optimum. Section 5 concludes.

\section{The Model}

Two countries $i, i=h, f$, produce a homogeneous output from capital. The input of capital generates two types of pollution which differ with respect to the scale of their geographical impact. For simplicity we assume the two countries to be identical with respect to their production technologies as well as preferences. It is assumed that neither capital nor goods or labor are exchanged between the two countries, such that we can fully concentrate on the local and global environmental externalities.

The externality created by the first type of pollution, $P_{G}$, is of a global nature, i.e. it affects production in both countries. The obvious example that comes to mind is the case of $\mathrm{CO}_{2}$. Due to the long-period of time it takes for $\mathrm{CO}_{2}$ to be absorbed in the atmosphere, we assume that these emissions build up a renewable pollution stock, $S$,

\footnotetext{
${ }^{5}$ For a review of the literature on economic development and pollution with a focus on more recent endogenous growth based approaches, see Pittel (2002).
} 
that degenerates at rate $a$. As both countries generate pollution, the pollution stock dynamics are given by

$$
\dot{S}=P_{G}^{h}+P_{G}^{f}-a S
$$

with $\dot{S}=\frac{\mathrm{d} S}{\mathrm{~d} t}$. For simplicity we assume that capital, $K$, generates pollution in a constant emission ratio $p_{G}$. The emission of pollution can be reduced by abatement, $A_{L G},{ }^{6}$ such that $P_{G}$ reads

$$
P_{G}^{i}=p_{G} \frac{K^{i}}{A_{L G}^{i}}, \quad i=h, f .
$$

The second type of pollution we consider, $P_{L}$, induces a negative local externality that only affects production negatively in the country in which it is generated. Examples for this type of pollution might be emission of $\mathrm{SO}_{2}$ or $\mathrm{NO}_{x}$ that lead to, e.g., acid rain in a limited regional range around the point of emission. Having these types of pollution in mind, $P_{L}$ is assumed to give rise to a flow externality. ${ }^{7}$ Again we assume pollution to be generated in fixed proportions to the input of capital. The environmental impact of local pollution is reduced by abatement activities $A_{L G}$ that decrease global as well as local pollution and by abatement activities $A_{L}$ that specifically aim the reduction of local pollution. $P_{L}$ as a function of capital and the two types of abatement then reads

$$
P_{L}^{i}=p_{L} \frac{K^{i}}{\left(A_{L}^{i}\right)^{\alpha}\left(A_{L G}^{i}\right)^{1-\alpha}}, \quad 0<\alpha<1
$$

with $p_{L}$ denoting the emission intensity of capital.

Output, $Y$, is produced using a linear AK-technology in the tradition of Rebelo (1991). Both, the global pollution stock and local pollution flow, exert negative effects on production:

$$
Y^{i}=K^{i}\left(P_{L}^{i}\right)^{-\gamma} S^{-\delta}, \quad \gamma, \delta>0, \gamma+\delta<1 .
$$

It is assumed that the negative productivity effects from the input of capital, i.e. from pollution, do not overcompensate the positive effects $(1-\gamma-\delta>0)$. Output can be used for consumptive, investive and abatement purposes, such that the equilibrium condition for the capital market reads

$$
\dot{K}^{i}=Y^{i}-C^{i}-A_{L}^{i}-A_{L G}^{i} .
$$

\footnotetext{
${ }^{6}$ As $A_{L G}$ reduces local as well as global pollution, it is indexed $L G$ thus referring to Local and Global.

${ }^{7}$ This is of course an approximation which seems, however, justifiable when comparing the degradation rates of, e.g., $\mathrm{SO}_{2}$ induced pollution to $\mathrm{CO}_{2}$.
} 
Finally, households in each country $i$ derive utility from consumption $C$. The representative household maximizes discounted lifetime utility with respect to its intertemporal budget constraint:

$$
\begin{array}{lll}
\max _{c} & \int_{0}^{\infty} \frac{C^{i}(t)^{1-\sigma}}{1-\sigma} e^{-\rho t} \mathrm{~d} t & \sigma \neq 1 \\
\text { s.t. } & \dot{W}^{i}=r^{i} W^{i}-C^{i} &
\end{array}
$$

where $W$ denotes total household asset holdings and $\rho$ is the discount rate.

\section{The Planner Solutions}

In the following we distinguish between different types of planner solutions: First, it is assumed that the planner only internalizes the local pollution externality but completely neglects the global externality. Second, he internalizes the effects of local and global pollution on the domestic economy but does not take into account that domestic $\mathrm{CO}_{2}$-emissions also cause damages abroad. Third, we consider the social planner solution in which both externalities are perfectly internalized, independently of where the damages arise. In a final subsection we then assume the internalization regimes to differ across countries, i.e. we consider asymmetric internalization.

\subsection{Scenario 1: Internalization of the Local Externality Only}

The planner in each country maximizes intertemporal utility of the representative household, (6), subject to capital accumulation, (5). After inserting (3) and (4) the corresponding Hamiltonian in Scenario 1 for each country reads

$$
\begin{aligned}
H_{1}^{i}\left(C^{i}, K^{i}, A_{L}^{i}, A_{L G}^{i}, \lambda^{i}\right)= & \frac{\left(C^{i}\right)^{1-\sigma}}{1-\sigma} e^{-\rho t} \\
& +\lambda^{i}\left(p_{L}^{-\gamma}\left(K^{i}\right)^{1-\gamma}\left(A_{L}^{i}\right)^{\alpha \gamma}\left(A_{L G}^{i}\right)^{(1-\alpha) \gamma} S^{-\delta}-C^{i}-A_{L G}^{i}-A_{L}^{i}\right)
\end{aligned}
$$

where $\lambda$ is the shadow price of capital. Optimization gives rise to the following firstorder conditions

$$
\begin{aligned}
\left(C^{i}\right)^{-\sigma} e^{-\rho t} & =\lambda^{i} \\
\alpha \gamma \frac{Y^{i}}{A_{L}^{i}} & =\gamma(1-\alpha) \frac{Y^{i}}{A_{L G}^{i}}=1 \\
g_{\lambda^{i}} & =-(1-\gamma) \frac{Y^{i}}{K^{i}}
\end{aligned}
$$


and the transversality condition for the capital stock, $\lim _{t \rightarrow \infty} \lambda^{i} K^{i}=0 . g_{\lambda}=\frac{\dot{\lambda}}{\lambda}$ is the growth rate of $\lambda$.

From (8) and (10) we get the familiar Keynes-Ramsey rule

$$
g_{C}^{i}=\frac{1}{\sigma}\left((1-\gamma) Y_{K}^{i}-\rho\right)
$$

where $Y_{K}^{i}=\frac{Y^{i}}{K^{i}}$ denotes the output-capital-ratio. $(1-\gamma) Y_{K}^{i}$ gives the marginal product of capital net of local pollution effects.

It will prove useful for the further analysis to determine the capital-abatement ratio $K_{A}=\frac{K}{A_{L G}}$ as an indicator of the environmental friendliness of a growth path. The higher $K_{A}$, the higher the input of polluting capital in relation to pollution reducing abatement $A_{L G}$. Alternatively, we could have chosen the capital-abatement ratio with respect to $A_{L}$. In Scenario 1 an increase in $A_{L G}$ always implies a simultaneous increase in $A_{L}$ as (9) shows that the two abatement activities will be employed in a constant ratio that is determined by their respective productivity in reducing local pollution:

$$
\frac{A_{L G}^{i}}{A_{L}^{i}}=\frac{1-\alpha}{\alpha} .
$$

The simple relation in (12) is of course due to the neglect of stock pollution by the planner. The mitigating effect of $A_{L G}$ on global pollution is not reflected in (12) such that the ratio is biased towards local pollution abatement (see also Subsection 3.3).

Using (4) and (12), $K_{A}$ can be expressed as a function of $S$ only:

$$
K_{A}^{i}=[\gamma(1-\alpha)]^{-\frac{1-\alpha \gamma}{1-\gamma}}\left[\frac{p_{L}^{\gamma} S^{\delta}}{b(\alpha \gamma)^{\alpha \gamma}}\right]^{\frac{1}{1-\gamma}} .
$$

As $K_{A}^{i}$ only depends on the pollution stock and no country specific variables, the capital-abatement ratio will be identical across countries, i.e. $K_{A}^{h}=K_{A}^{f}$, at any point in time. ${ }^{8}$ (13) also shows the positive relation between $K_{A}$ and the pollution stock, i.e. a higher $S$ is due to less abatement relative to capital accumulation.

From (9), the capital-abatement ratio can be expressed as $Y_{K}^{i}=\left[\gamma(1-\alpha) K_{A}^{i}\right]^{-1}$ where $K_{A}$ is determined by (13). The dynamics of consumption, (11), can thus be rewritten in terms of the capital-abatement ratio:

$$
g_{C}^{i}=\frac{1}{\sigma}\left(\frac{1-\gamma}{\gamma(1-\alpha)} \frac{1}{K_{A}^{i}}-\rho\right)
$$

\footnotetext{
${ }^{8}$ In case of differences in the countries' technologies and/or preferences, $K_{A}$ would of course differ across countries, yet would still only be influenced by the other country through the pollution stock.
} 
As $K_{A}$ depends positively on the pollution stock, a higher $S$ implies lower growth.

Along any balanced growth path (BGP), ${ }^{9} g_{Y}^{i}=g_{C}^{i}=g_{K}^{i}=g_{A_{L}}^{i}=g_{A_{L G}}^{i}$ and $g_{S}=0$ hold. The pollution stock along the BGP is constant and given by

$$
S=\frac{p_{G}\left(K_{A}^{h}+K_{A}^{f}\right)}{a}=2 \frac{p_{G} K_{A}^{i}}{a}
$$

as the capital-abatement ratio is equal across countries. Consequently, $K_{A}^{i}$ in the long-run equilibrium is given by

$$
K_{A}^{i}=(\gamma(1-\alpha))^{-\frac{1-\alpha \gamma}{1-\gamma-\delta}}\left(\frac{p_{L}^{\gamma}\left(\frac{2 p_{G}}{a}\right)^{\delta}}{(\alpha \gamma)^{\alpha \gamma}}\right)^{\frac{1}{1-\gamma-\delta}}
$$

The RHS of (16) depends positively on the elasticity of output with respect to stock pollution, $\delta$, as well as on the pollution intensities of capital, $p_{L}$ and $p_{G}$. For any given capital input and level of abatement, an increase in either of these parameters reduces output and thereby the marginal product of abatement. Thus the planner finds its optimal to increase the capital-abatement ratio until the marginal product of abatement is again equal to its marginal costs. As a result, interestingly, a stronger effect of pollution on production induces a higher capital-abatement ratio and therefore higher pollution.

The same effect arises with respect to $\gamma$, the elasticity of output with respect to flow pollution. Yet, an increase in $\gamma$ also affects the marginal product of abatement positively as abatement becomes more productive, see (9). Depending on which of the two effects dominates, $K_{A}$ rises or falls with $\gamma$. As can be seen from $\frac{\partial K_{A}^{i}}{\partial \gamma}=$ $\frac{K_{A}^{i}\left[\log \left(P_{L}^{i}\right)-1 / \gamma\right]}{1-\gamma-\delta}$, the higher the equilibrium pollution flow, the more likely $K_{A}^{i}$ increases with $\gamma$.

It can be shown that the BGP is locally saddle-path stable by rewriting the dynamic system in terms of $S$ and the consumption-capital-ratio, $C_{K}^{i}$, which is constant along the BGP. From (1), (5) and (14) we get

$$
\begin{aligned}
\dot{S} & =2 p_{G} K_{A}^{i}(S)-a S \\
\dot{C}_{K}^{i} & =\left(\frac{1-\sigma}{\sigma} \frac{1-\gamma}{\gamma}(1-\alpha) K_{A}^{i}(S)^{-1}-\frac{\rho}{\sigma}-C_{K}^{i}\right) C_{K}^{i} .
\end{aligned}
$$

\footnotetext{
${ }^{9} \mathrm{~A}$ BGP or long-run equilibrium is defined as a growth path along which all variables grow at constant rates.
} 
The eigenvalues in the proximity of the steady state are $E V_{1}=C_{K}^{i}>0$ and $E V_{2}=$ $-a \frac{1-\gamma-\delta}{1-\gamma}<0 . E V_{2}$ is negative as we have assumed that the externalities from capital do not outweigh its positive effect on production $(1-\gamma-\delta>0)$. As one eigenvalue is negative and our system contains one jump variable and one predetermined variable, the economy is saddle-path stable.

\subsection{Scenario 2: Decentral Internalization of the Global Externality}

In contrast to the previous section, we now assume that the planner in each country takes the effects of global pollution on its own economy into account yet fails to internalize its transnational effects. The planner maximizes intertemporal welfare subject to the equations of motion of the capital stock as well as of the pollution stock. The corresponding Hamiltonian is given by

$$
H_{2}^{i}\left(C^{i}, K^{i}, A_{L}^{i}, A_{L G}^{i}, S, \lambda^{i}, \mu^{i}\right)=H_{1}^{i}(\cdot)+\mu^{i}\left(p_{G}\left(K_{A}^{i}+K_{A}^{j}\right)-a S\right)
$$

where $H_{1}^{i}(\cdot)$ is given in (7) and $\mu$ denotes the shadow price of the pollution stock which is negative. Due to the internalization of $S$, the FOCs for $A_{L G}$ and $K$ are modified. Together with an additional FOC for the pollution stock, the modified FOCs read after some rearranging

$$
\begin{aligned}
\gamma(1-\alpha) Y_{K}^{i} K_{A}^{i} & =1+\frac{\mu^{i}}{\lambda^{i}}\left(p_{G} \frac{1}{A_{L G}^{i}}\right) K_{A}^{i} \\
g_{\lambda^{i}} & =-(1-\gamma) Y_{K}^{i}-\frac{\mu^{i}}{\lambda^{i}}\left(p_{G} \frac{1}{A_{L G}^{i}}\right) \\
g_{\mu^{i}} & =\frac{\lambda^{i}}{\mu^{i}}\left(\frac{\delta}{S} \frac{1}{A_{L G}^{i}}\right)^{-1} Y_{K}^{i} K_{A}^{i}+a
\end{aligned}
$$

plus the transversality condition $\lim _{t \rightarrow \infty} \mu^{i} S=0$.

In comparison to (9), the additional term on the RHS of (17) represents the internalized return to $A_{L G}$ from mitigating global pollution. The return is the higher, the higher the negative impact of pollution on welfare relative to the positive welfare effect from capital accumulation, i.e. $\left|\frac{\mu^{i}}{\lambda^{i}}\right|$, and the higher the marginal impact of abatement on pollution, i.e. the higher $\left|\frac{\partial P_{G}}{\partial A_{L G}}\right|=p_{G} \frac{K_{A}^{i}}{A_{L G}^{i}}$. Due to the additional return from $A_{L G}$, the optimal ratio of $A_{L G}$ to $A_{L}$ rises in comparison to Scenario $1\left(\frac{A_{L G}^{i}}{A_{L}^{i}}>\frac{1-\alpha}{\alpha}\right)$. With respect to (18) and (10), the additional term in (18) reflects the internalized costs of capital in terms of global pollution. Finally, (19) gives the dynamics of $\mu$, the shadow 
price of the pollution stock. The growth rate of $\mu$ is determined by the marginal costs accruing from an additional unit of emissions $P_{G}$. These costs equal output foregone due to a marginal addition to the capital stock net of the regeneration rate of $S$.

From the FOCs we get the modified capital-abatement ratio along the BGP (for the derivation see Appendix 6.1)

$$
K_{A}^{i}=\left(\gamma(1-\alpha)+\frac{1}{2} \frac{\delta a}{C_{K}^{i}+a}\right)^{-\frac{1-\alpha \gamma}{1-\gamma-\delta}}\left(\frac{p_{L}^{\gamma}\left(\frac{2 p_{G}}{a}\right)^{\delta}}{(\alpha \gamma)^{\alpha \gamma}}\right)^{\frac{1}{1-\gamma-\delta}} .
$$

Comparison with (16) shows that the equilibrium capital-abatement ratio in (20) is lower due to the internalization of the global externality. The additional term in (20) reflects the reduced incentives to invest in capital due to the negative effect on productivity from global pollution. The higher the elasticity of production with respect to stock pollution, i.e. the higher $\delta$, the lower the optimal capital-abatement ratio is compared to Scenario 1. Dependency of the additional term on the consumptioncapital ratio, $C_{K}$, reflects that a higher share of output consumed compared to output invested lowers the stress on the environment. As a result, the detrimental effect on the capital-abatement ratio is lower for higher values of $C_{K}$.

From (15) it follows immediately that the pollution stock along the BGP is the lower, the lower the capital-abatement ratio. So, as to be expected, internalization of the global externality induces the long-run pollution stock to fall. ${ }^{10}$

The modified growth rate of consumption is given by (for the derivation see Appendix 6.1):

$$
\begin{aligned}
g_{C}^{i} & =\frac{1}{\sigma}\left((1-\alpha \gamma) Y_{K}^{i}-\frac{1}{K_{A}^{i}}-\rho\right) \\
& =\frac{1}{\sigma}\left(\frac{(1-\gamma)-\frac{1}{2} \frac{\delta a}{C_{K}^{i}+a}}{\gamma(1-\alpha)+\frac{1}{2} \frac{\delta a}{C_{K}^{i}+a}} \frac{1}{K_{A}^{i}}-\rho\right) .
\end{aligned}
$$

\footnotetext{
${ }^{10}$ The stability of the transition path under imperfect internalization can be analyzed using a $5 \times 5$ dynamic system that considers the development of $C_{K}^{h}, C_{K}^{f}, K_{A}^{h}, K_{A}^{f}$ and $S$. As the capital-abatement ratio in (20) now depends on the consumption-capital ratio, the countries can follow different transitional paths although $K_{A}$ will be equal across countries along the BGP due to our simplifying assumption of identical economies. The resulting eigenvalues' functional forms are quite involved, yet it can be shown numerically that the system has one negative and four positive eigenvalues for a wide range of parameter values. Consequently, the system is saddle-path stable as it contains one predetermined and four jump variables.
} 
Comparison of (22) with (14) shows that internalization of the stock externality gives rise to two opposing effects on the growth rate - which effect dominates, depends on the parametrization of the model.

On the one hand, the decline of the capital-abatement ratio affects growth positively. On the other hand, (22) now accounts explicitly for the growth reducing effect of the stock externality. We see from (14) that in Scenario 1 the marginal productivity of $K_{A}$ depends on $\gamma$ and $(1-\alpha)$ which determine the respective productivities of capital and abatement. Internalization of $S$ in (22) induces the marginal productivity to additionally depend on the externality from stock pollution, $\frac{1}{2} \frac{\delta a}{C_{K}^{i}+a}$. Internalization lowers the productivity of capital $\left(-\frac{1}{2} \frac{\delta a}{C_{K}^{i}+a}\right)$ but increases the productivity of abatement $\left(+\frac{1}{2} \frac{\delta a}{C_{K}^{i}+a}\right)$.

From (4) and the FOC for $A_{L}$ in (9), we get an expression for the output-capital ratio that solely depends on the capital-abatement ratio

$$
Y_{K}^{i}=\left(p_{L}^{-\gamma}(\alpha \gamma)^{\alpha \gamma}\left(\frac{2 p_{G}}{a}\right)^{-\delta}\right)^{\frac{1}{1-\alpha \gamma}}\left(K_{A}^{i}\right)^{-\frac{(1-\alpha) \gamma+\delta}{1-\alpha \gamma}} .
$$

As (23) only reflects the production technology and the optimal input of $A_{L}$, the same functional relationship between $Y_{K}$ and $K_{A}$ holds in Scenario 1. Yet, as the optimal capital-abatement ratio is lower in Scenario 2 than in Scenario 1, the output-capital ratio is higher. Multiplying (23) by $K_{A}^{i}$ gives $Y_{A}^{i}$, the output-abatement ratio, which positively depends on $K_{A}$. Thus, the share of output used for abatement rises due to the internalization of $P_{G}$.

Whether the consumed share of output, $C_{Y}^{i}$, rises, depends crucially on whether capital or abatement react stronger to the internalization. (5), (21) and the FOC for $A_{L}$ give - considering that $g_{C}=g_{K}$ along the BGP - the long-run consumption-output ratio

$$
C_{Y}^{i}=\frac{C^{i}}{Y^{i}}=\frac{\sigma-1}{\sigma}\left((1-\alpha \gamma)-\left(K_{A}^{i} Y_{K}^{i}\right)^{-1}\right)+\frac{\rho}{\sigma}\left(Y_{K}^{i}\right)^{-1}
$$

Using (5), (9) and (11) it can be shown that (24) also holds in Scenario 1.

When comparing $C_{Y}$ in Scenario 1 and 2, recall that $K_{A}^{i}$ and $Y_{K}^{i}$ differ in the two scenarios. As the output-capital ratio in Scenario 2 is higher than in Scenario 1, a higher share of output is available for non-investive purposes which exerts a positive effect on $C_{Y}$. Additionally, internalization and the associated change in the returns to abatement and capital induce the planner to devote a larger share of output to abatement, such that $\frac{Y^{i}}{A_{L G}^{i}}=Y_{K}^{i} K_{A}^{i}$ rises. Whether this has a positive or negative 
effect on the consumed share of output depends crucially on $\sigma \lesseqgtr 1$, i.e. on whether the intertemporal substitution or income effect following a change in the return on investment dominates. ${ }^{11}$

Although we have seen that the capital-abatement ratio and the pollution stock are lower than in Subsection 3.1, they are still suboptimal. As so far neither country internalizes the negative spill-overs of its emissions on the other country, the capitalabatement ratio as well as the pollution stock are still suboptimally high as will be shown in the next subsection.

\subsection{Scenario 3: Perfect Internalization}

It is now assumed that both countries internalize the negative effects of their own emissions not only on the domestic economy but also on the other country. As all market failures are perfectly internalized, the resulting growth path is identical to the growth path a global social planner would choose. The corresponding Hamiltonian considers the development in both countries and therefore reads

$$
H_{3}\left(C^{i}, K^{i}, A_{L}^{i}, A_{L G}^{i}, S, \lambda^{i}, \mu\right)=\sum_{i} H_{1}^{i}(\cdot)+\mu\left(p_{G}\left(K_{A}^{h}+K_{A}^{f}\right)-a S\right) .
$$

The resulting set of FOCs for each country is identical to the one of the previous section with exception of the FOC for the pollution stock which now reads

$$
g_{\mu}=\frac{\delta}{S}\left(\frac{\mu}{\lambda^{h}} \frac{1}{A_{L G}^{h}}\right)^{-1} Y_{K}^{h} K_{A}^{h}+\frac{\delta}{S}\left(\frac{\mu^{f}}{\lambda^{f}} \frac{1}{A_{L G}^{f}}\right)^{-1} Y_{K}^{f} K_{A}^{f}+a .
$$

(25) reflects that an increase of the pollution stock induces negative externalities in both countries which reduce the value of the joint objective function.

Following the same line of reasoning as in the previous scenario, it can be shown that the modified capital-abatement ratio along the BGP is given by

$$
K_{A}^{i}=\left(\gamma(1-\alpha)+\frac{\delta a}{C_{K}^{i}+a}\right)^{-\frac{1-\alpha \gamma}{1-\gamma-\delta}}\left(\frac{p_{L}^{\gamma}\left(\frac{2 p_{G}}{a}\right)^{\delta}}{b(\alpha \gamma)^{\alpha \gamma}}\right)^{\frac{1}{1-\gamma-\delta}}
$$

The first term on the RHS of (26) shows the effect of integrating foreign damages from domestic pollution. Compared to Scenario 2, perfect internalization doubles

\footnotetext{
${ }^{11}$ Please note that by inserting (23) and (24) into (20) it can be shown that (20) determines a unique equilibrium value of $K_{A}^{i}$.
} 
the feedback effect of stock pollution damages on the capital-abatement ratio. This induces a further decline of $K_{A}^{i}$ and - as follows straightforwardly - the pollution stock.

The BGP growth rates of the economies are still given by (21). Inserting (26) gives

$$
g_{C}^{i}=\frac{1}{\sigma}\left(\frac{(1-\gamma)-\frac{\delta a}{C_{K}^{i}+a}}{\gamma(1-\alpha)+\frac{\delta a}{C_{K}^{i}+a}} \frac{1}{K_{A}^{i}}-\rho\right) .
$$

As the case with respect to $K_{A}^{i}$ in (26), perfect internalization strengthens the effects observable in Scenario 2. Whether, however, the growth rate rises or falls due to the internalization of foreign damages again depends on the parametrization of the model.

\subsection{Scenario 4: Asymmetric Internalization}

So far, it was assumed that all countries internalize the global and the local externality symmetrically, yet the current debate on climate policies shows that this is hardly the case. In reality, a number of countries largely ignore global externalities and focus solely on the internalization of local externalities. This holds especially for developing countries - although not exclusively - while industrialized, higher income countries tend to take the feedback effects of the global externality (at least on their own economy) into account. This is, for example, reflected by the fact that all industrialized countries (except for the US) committed to GHG emission reductions by ratifying the Kyoto Protocol. Although our simplified set-up assumes that both countries are identical with respect to preferences as well as production technologies such that our analysis does not account for the systemic differences between developing and industrialized economies, we can derive basic implications on growth, abatement and pollution that result from asymmetric internalization strategies.

In this section we assume that country $h$ internalizes the local and the global externality while country $f$ solely takes the local externality into account. Under this assumption, the optimization problem of country $f$ again leads to the Hamiltonian of Subsection 3.1 such that its optimal capital-abatement ratio is given by (13)

$$
K_{A}^{f}=(\gamma(1-\alpha))^{-\frac{1-\alpha \gamma}{1-\gamma}}\left(\frac{p_{L}^{\gamma} S^{\delta}}{b(\alpha \gamma)^{\alpha \gamma}}\right)^{\frac{1}{1-\gamma}}
$$

Assuming that country $h$ takes the repercussions of global pollution at home but not abroad into account, its optimization problem is represented by the Hamiltonian of 
Subsection 3.2. ${ }^{12}$ In this case its capital-abatement ratio is equal to

$$
K_{A}^{h}=\left(\gamma(1-\alpha)+\frac{\delta a}{C_{K}^{h}+a} \frac{K_{A}^{h}}{K_{A}^{h}+K_{A}^{f}}\right)^{-\frac{1-\alpha \gamma}{1-\gamma}}\left(\frac{p_{L}^{\gamma} S^{\delta}}{b(\alpha \gamma)^{\alpha \gamma}}\right)^{\frac{1}{1-\gamma}}
$$

which is always lower than $K_{A}^{f}$ in (13).

Compared to Scenario 1, country $h$ finds a lower capital-abatement ratio optimal due to the internalization of the global externality such that it pollutes less. This reduces the equilibrium pollution stock below the equilibrium level of Scenario 1. As a consequence, country $f$ lowers $K_{A}^{f}$, such that it pollutes less than in Scenario 1 but still more than in Scenario 2. As a result, the pollution stock and thus $K_{A}^{h}$ are higher than in Scenario 2 as well.

Also, local pollution in country $f$ decreases compared to a situation with symmetric internalization as $K_{A}^{f}$ is lower. Furthermore, as the two abatement activities are conducted at the fixed ratio $\frac{1-\alpha}{\alpha}$ in country $f$, investment in $A_{L}$ also increases relative to the capital stock which reduces local pollution further.

Country $h$ experiences the opposite: Due to higher global pollution in comparison to a situation with symmetric internalization, it conducts relatively less $A_{L G}$. Parallel to the development in country $h$, this induces a decrease in $A_{L}$, thus strengthening the effect on local pollution. So, in both countries the assumption of asymmetric internalization not only affects the level of abatement regarding global pollution but spills over to the abatement of local pollution.

From the preceding analysis of the planner solutions, the straightforward question arises, how the different scenarios could be implemented in a market economy. Depending on the degree of internalization of the externalities, the instruments to be employed as well as their optimal level will vary. Of special interest is the question of optimal policies in the asymmetric case. How should the policy maker in country $h$ optimally react if country $f$ ignores the global externality?

\footnotetext{
${ }^{12}$ Alternatively, we could assume that country $h$ does consider international spill-overs (in which case it would maximize the Hamiltonian of Subsection 3.3). Yet - comparable to the results of Scenario 2 and 3 presented previously - no additional qualitative effects would arise as only the magnitude of the effects would change.
} 


\section{Market Solution and Environmental Policies}

\subsection{Symmetric Scenarios 1 to 3}

Let us first consider optimal policies a policy maker would adopt in the symmetric Scenarios 1 to 3 . As the market failures are solely due to environmental externalities, we only have to consider the optimal design of environmental policy. Compared to an economy in which market failures additionally arise from, e.g., knowledge spill-overs or monopolistic competition as in Grimaud and Rougé (2003) or Pittel and Bretschger (2009), this renders the analysis more straightforward.

In Scenario 1, both countries ignore the global externality such that only the local externality remains to be internalized. In reality, the policy maker can obviously choose between the implementation of different instruments. In this paper, however, we stick for simplicity to environmental taxation and assume that a $\operatorname{tax} \tau_{L}$ is levied on local pollution $P_{L}$. (In the following we drop country indices for convenience as optimal policies in both countries are identical along the BGP in the symmetric scenarios. $)^{13}$

In the market economy, households maximize their intertemporal utility subject to their budget constraint as given in (6) which yields the standard Keynes-Ramsey rule

$$
g_{C}=\frac{1}{\sigma}(r-\rho)
$$

Firms maximize profits which gives rise to FOCs for the two types of abatement and capital. As individual firms do not internalize the externalities arising from pollution, their return to abatement solely consists in the taxes saved due to abatement. Consequently, the FOCs for abatement and capital read

$$
\begin{aligned}
1 & =(1-\alpha) \tau_{L} \frac{P_{L}}{A_{L G}}=\alpha \tau_{L} \frac{P_{L}}{A_{L}} \\
r & =Y_{K}-\tau_{L} \frac{P_{L}}{K} .
\end{aligned}
$$

The optimal policy in this case is given by

$$
\tau_{L}=\gamma \frac{Y}{P_{L}}
$$

i.e. the optimal tax rate has to equal the marginal externality. Inserting (32) into the above FOCs and the Keynes-Ramsey rule replicates the growth path of Scenario

\footnotetext{
${ }^{13}$ Please note, that the stability properties of the system during the transition to the BGP are of course identical to those of the planner scenarios when the planner conducts an optimal policy.
} 
1. From (32) follows that the tax rate has to rise over time in order to mirror the increasing scarcity of pollution in a growing economy.

In Scenario 2 both planners internalize the local and the domestic effects of the global externality. As two different externalities are now considered, each policy maker requires two instruments to internalize both. Although both pollution types arise as a constant share of the capital input, two instruments are necessary as the induced market failures are not perfectly correlated - in which case one policy instrument would be sufficient. ${ }^{14}$ In addition to the tax on local pollution we now consider a second tax on the emission of the global pollutant, $\tau_{G}$.

Due to the additional tax the FOCs for $A_{L G}$ and $K$ now read

$$
\begin{aligned}
1 & =(1-\alpha) \tau_{L} \frac{P_{L}}{A_{L G}}+\tau_{G} \frac{P_{G}}{A_{L G}} \\
r & =Y_{K}-\tau_{L} \frac{P_{L}}{K}-\tau_{G} \frac{P_{G}}{K}
\end{aligned}
$$

while the FOC for $A_{L}$ remains unchanged. As the local externality was already perfectly internalized in Scenario 1, the optimal tax rule for local pollution is again given by (32). The optimal tax on $P_{G}$ can then be shown to equal the marginal externality arising from global pollution (see Appendix 6.2)

$$
\tau_{G}=\delta \frac{Y}{S} \frac{1}{C_{K}+a} .
$$

Recall that (32) equalized the tax rate on local pollution, $\tau_{L}$, to the marginal damages caused by $P_{L}$ today, $\gamma \frac{Y}{P_{L}}$. Equivalently, the marginal externality from $P_{G}$, i.e. $\delta \frac{Y}{S}$ appears in (35). Yet, the optimal $\tau_{G}$ is also determined by a second term, $\frac{1}{C_{K}+a}$, that accounts for future externalities from today's addition to the stock of pollution. The tax rate depends therefore negatively on the regeneration rate $a$, as faster regeneration implies that pollution is absorbed faster. Also, a higher consumption-capital ratio, i.e. lower investment in (polluting) capital compared to consumption, means that less pollution is generated from today's production and therefore less is added to the pollution stock.

Finally, let us consider Scenario 3 in which the same two externalities are internalized as in Scenario 2 such that the same tax instruments can be employed.

\footnotetext{
${ }^{14}$ Employing a unified tax rate on capital in this scenario could generate the optimal growth rate, but would not lead to an optimal abatement mix as the price ratio between the two abatement types would remain distorted.
} 
Regarding the local externality, (32) still represents the optimal tax rule while (35) has to be adjusted in order to capture the international spill-overs from global pollution. Recalling the results for Scenario 3, it follows straightforwardly that $\tau_{G}$ has to be doubled, i.e.

$$
\tau_{G}=2 \delta \frac{Y}{S} \frac{1}{C_{K}+a}
$$

in order to account for the (identical) damages from $P_{G}$ caused at home and abroad.

\subsection{Asymmetric Scenario 4}

Given that, as assumed in Scenario 4, the two countries do not follow the same internalization strategy, the question arises which policy mix is optimal in this case. Let us consider two different assumptions about the countries' behavior successively.

First, assume that either country takes the pollution that is generated in the other country as exogenous. In this case the optimal policy rules are identical to those derived in the previous subsection. More specifically, both countries would set the local pollution tax according to (32) and country $h$ would tax $P_{G}$ according to (35). Yet, although the policy rules are the same as in Subsection 4.1, the absolute levels and growth rates of taxation would be different. As the stock of pollution in Scenario 4 is neither identical to Scenario 1 nor to Scenario 2, optimal growth and the optimal level of economic activities also differ from Scenario 1 and 2 which entails different values of the optimal tax rates.

Second, assume that the countries realize that the other country is following a different internalization strategy. In this case they would perceive the outcome of the previous paragraph as suboptimal. Country $h$, for example, would perceive global pollution as too high compared to the symmetric Scenario 2. This case constitutes the probably most realistic situation with respect to the current political situation. One group of countries - here subsumed by country $h$ - aims at the internalization of the damages from global pollution while another group of countries - here represented by country $f$ - still ignores global externalities completely in its policy making. ${ }^{15}$

\footnotetext{
${ }^{15}$ Additionally, one could of course consider all other combinations of internalization strategies between the two countries, for example, the case in which one country internalizes only domestic externalities from $P_{G}$ while the other internalizes the global externality perfectly. As, however, the basic implications for policy making remain the same, we focus on the above described combination of strategies.
} 
One option for country $h$ to attain the optimal pollution stock of Scenario 2 could be to tax domestic pollution, local and/or global, at different rates than in the previous sections. First, it could choose to tax global pollution at a higher rate, thus inducing a further reduction which would yield as ancillary benefit an accompanying reduction of local pollution. This policy can, however, not be optimal. Under the policy rules we derived in the previous sections, country $h$ sets the tax rate, $\tau_{G}$, equal to the marginal damage from pollution. For a $\tau_{G}$ above this level, the marginal damages would be smaller than the tax rate which would lower welfare. If the country would - as compensation for the higher $\tau_{G}$ - lower the tax on local pollution, this could result in the optimal local and global pollution levels, yet the costs of attaining these optimal levels would be suboptimally high as the price ratio between the two types of pollution would be distorted.

A second option would be to subsidize either pollution reduction or abatement in country $f$. Subsidizing pollution reduction would leave the receiving country the choice to reduce capital accumulation and/or abatement in order to reduce $P_{G}$ while abatement subsidies solely set incentives to increase abatement activities. As we will show in the following, the two policies, although closely related, have very different implications for global welfare and especially the receiving country.

\section{Subsidy on Pollution Reduction}

First consider a subsidy to pollution reduction, $s_{P}$, i.e. country $h$ pays for a reduction of $P_{G}^{f}$ below its status quo level. ${ }^{16}$ In a world with perfect information this is feasible since status quo pollution in country $f$ is known to the policy maker in country $h$. In reality, in which such perfect information may not be given, this policy would, however, set incentives for the country $f$ to exaggerate its pre-subsidization pollution. If we stick to the assumption that no information related market failure arises, optimal policy in this case is straightforward.

Profits of firms in country $f$ are given by

$$
\Pi^{f}=Y^{f}-r^{f} K^{f}-A_{L}^{f}-A_{L G}^{f}-\tau_{L}^{f} P_{L}^{f}+s_{G}\left(\bar{P}_{G}-P_{G}^{f}\right)
$$

where $\bar{P}_{G}$ denotes the status quo level of pollution. Optimization leads to the following

\footnotetext{
${ }^{16}$ Status quo level refers to the level of pollution under sole internalization of the local externality in country $f$. For simplicity we assume that subsidies are financed by lump-sum taxation in country $h$.
} 
FOCs:

$$
\begin{aligned}
\gamma(1-\alpha) Y_{K}^{f} K_{A}^{f} & =1-s_{G} \frac{p_{G} K_{A}^{f}}{A_{L G}^{f}} \\
\alpha \gamma \frac{Y^{f}}{A_{L}^{f}} & =1 \\
r & =(1-\gamma) Y_{K}^{f}-s_{G} \frac{p_{G}}{A_{L G}^{f}}
\end{aligned}
$$

where we have already considered that country $f$ sets the tax rate on local pollution at its optimal level, i.e. $\tau_{L}=\gamma \frac{Y}{P_{L}}$. Comparison of (39) to Scenario 2 shows that the FOC for $A_{L}$ is corrected for by $\tau_{L}$. Further comparison of (38) and (40) to (17) and (18) reveals that the subsidy that induces the optimal growth path of Scenario 2 equals the negative ratio of the shadow prices for capital and stock pollution

$$
s_{G}=-\frac{\mu^{f}}{\lambda^{f}} .
$$

This implies that the optimal subsidy rate has to follow the same rule as the tax rate $\tau_{G}$ in country $h$. To induce country $f$ to reduce its pollution to the optimal level, country $h$ has to pay a marginal compensation which equals the marginal damages from pollution. As the marginal damages that arise from $P_{G}$ are independent from their geographical origin, the marginal avoided damage in country $f$ due to the subsidy exactly equals the marginal damage avoided in country $h$. Consequently, the subsidy equals each, the marginal damages at home and abroad, i.e.

$$
s_{G}=\tau_{G}=\delta \frac{Y^{h}}{S} \frac{1}{C_{K}^{h}+a}=\delta \frac{Y^{f}}{S} \frac{1}{C_{K}^{f}+a} .
$$

Thus, for country $h$ to induce optimal pollution, ${ }^{17}$ it has to forego its revenues from taxing $P_{G}^{h}$ to pay the subsidy to country $f$. If it receives no additional benefits from reducing pollution, country $h$ will be indifferent between subsidization and not intervening in country $f$. Hence, if raising and transferring the public funds needed for subsidization would be accompanied by any social costs, country $h$ would rationally decide not to subsidize country $f$. Country $f$, on the other hand, profits from the subsidy, as the externalities from global pollution decline and it additionally receives the subsidy from country $h$.

\footnotetext{
${ }^{17}$ Subsidization at rate $s_{G}$ from (42) induces $K_{A}^{f}$ as well as $g_{C}^{f}$ to be equal to the respective BGP values in Scenario 2, (20) and (22), see Appendix 6.3.
} 
In comparison to other possible subsidy schemes - as, e.g., subsidizing abatement (see next paragraph) - the advantage of subsidizing pollution reduction is that it corrects not only for the returns to $A_{L G}$-abatement but also for the returns to capital. The price ratios between the two abatement types as well as between abatement and capital are thus optimal. From a global perspective, subsidizing pollution reduction is optimal as it can achieve the first-best allocation, yet due to the uneven distribution of gains, this policy might not be implemented. As we will see in the next paragraph, abatement subsidization - the second option for country $h$ - might have a better chance of being implemented. Yet, while it equally corrects for the distortion in the relative price of the two abatement types, the price ratio between abatement and capital remains distorted and the first-best solution is consequently not implemented.

\section{Subsidy on Abatement}

In the real world, the advantage of subsidizing abatement in comparison to pollution reduction would be its better observability and thus the lower potential to exaggerate abatement activities in order to receive higher payments. In our world, however, information is perfect, such that observability plays no role regarding a comparison of the two instruments.

If country $h$ subsidizes abatement $A_{L G}$ at rate $s_{A}$, profits of firms in country $f$ are given by

$$
\Pi^{f}=Y^{f}-r^{f} K^{f}-A_{L}^{f}-\left(1-s_{A}\right) A_{L G}^{f}-\tau_{L}^{f} P_{L}^{f}
$$

which yields the following FOCs (assuming optimal taxation of $P_{L}^{f}$ )

$$
\begin{aligned}
\gamma(1-\alpha) Y_{K}^{f} K_{A}^{f} & =1-s_{A} \\
\alpha \gamma \frac{Y^{f}}{A_{L}^{f}} & =1 \\
r^{f} & =(1-\gamma) Y_{K}^{f} .
\end{aligned}
$$

Again, the price of $A_{L}$ is set equal to its social return. Comparison of the FOC for $A_{L G},(44)$, to (17) shows that the optimal subsidy rate has to equal

$$
s_{A}=-\frac{\mu^{f}}{\lambda^{f}} \frac{P_{G}^{f}}{A_{L G}^{f}}=s_{G} \frac{P_{G}^{f}}{A_{L G}^{f}} .
$$

In contrast to the subsidy on pollution reduction, the subsidy on abatement has to mirror not only the relative shadow price of pollution but also has to take the produc-

tivity of abatement in pollution reduction, $\left|\frac{\mathrm{d} P_{G}^{f}}{\mathrm{~d} A_{L G}^{f}}\right|=\frac{P_{G}^{f}}{A_{L G}^{f}}$, into account. Consequently, 
the higher the productivity, the more abatement is optimal and the higher the subsidy rate. The question arises whether this optimal subsidy rate is higher or lower than the induced marginal damage reduction in country $h$. As pollution is constant along the BGP while abatement increases over time, the ratio falls over time and approaches zero, such that $\frac{P_{G}^{f}}{A_{L G}^{f}}<1$ holds in the long run. ${ }^{18}$

Along the BGP, the falling ratio of pollution and abatement, $\frac{P_{G}^{f}}{A_{L G}^{f}}$, and the increase of the shadow price of pollution, $-\frac{\mu^{f}}{\lambda^{f}}$, exactly offset each other, such that the social return to abatement - and thus the subsidy rate $s_{A}$ - is constant over time. The aggregate abatement subsidy paid to country $f$, thus grows at rate $g_{A_{L G}}$.

The subsidy rate on pollution reduction, on the other hand, increases over time as pollution gets scarcer and thus more valuable. Taking into account that the pollution stock and $C_{K}$ are constant along BGP and that $g_{Y}=g_{A_{L G}}$, we see from (42) that $s_{G}$ grows at rate $g_{A_{L G}}$. As $P_{G}$ is constant over time, this implies that the aggregate subsidy on pollution reduction grows at the same rate as the aggregate subsidy on abatement.

So, although it might seem at first glance that country $h$ should favor subsidizing abatement in contrast to pollution reduction (as the respective subsidy rate does not increase over time), the expenditures for both subsidy schemes actually grow at the same rate.

With respect to the accumulation of capital, (46) shows that a subsidy on abatement does not affect the FOC for capital. As the subsidy does not capture the negative externality from capital, the return to capital as well as growth are higher than in Scenario 2. In order to show this, substitute (44) and (46) into the Keynes-Ramsey rule, (29), which gives the growth rate of country $f$ in terms of the capital-abatement ratio

$$
g_{c}^{f}=\frac{1}{\sigma}\left(\frac{1-\gamma}{\gamma(1-\alpha)} \frac{1}{K_{A}^{f}}\left(1-s_{A}\right)-\rho\right) .
$$

The growth rate in Scenario 2 would be given by (21) which, using (17) and (47), can be rewritten as

$$
g_{C}^{f}=\frac{1}{\sigma}\left(\frac{1-\gamma}{\gamma(1-\alpha)} \frac{1}{K_{A}^{f}}\left(1-\frac{1-\alpha \gamma}{1-\gamma} s_{A}\right)-\rho\right) .
$$

As the $K_{A}^{f}$ in (48) and (49) are identical if abatement is subsidized at rate (47), it

\footnotetext{
${ }^{18} s_{A}$ from (47) induces $K_{A}^{f}$ to be equal to (20), see Appendix 6.4.
} 
follows that country $f$ grows at a suboptimally high rate due to the uninternalized externalities from capital.

If country $h$ would not only internalize the domestic damages from $P_{L G}$ but also the transnational externalities, the gap between the growth rate under abatement subsidization and the optimal (in this case also first-best) growth rate would even be wider.

Summing up, subsidizing abatement or pollution reduction both succeed in attaining the optimal global pollution stock. Yet, the consequences for country $f$ and global welfare differ as under abatement subsidization country $f$ accumulates capital faster and therefore grows at a higher rate than is welfare optimal.

\section{Conclusions}

This paper analyzed local and global pollution in the framework of a 2-country endogenous growth model. It considered two different technologies to mitigate pollution, one of which reduced only local pollution while the other mitigated global pollution as well. We first derived implications for the optimal abatement mix, capital accumulation and growth under different assumptions about the degree to which the local and global externalities are internalized by a planner. Subsequently, policies were derived

in order to implement the growth paths of the different planner scenarios. Special attention was paid to the case of asymmetric internalization.

It was shown that pollution declines with an increasing degree of internalization while the effect on growth depends on the model's parametrization. Increasing the scope of internalization on the one hand hurts growth as relatively less capital is accumulated but also fosters growth as the productivity of capital increases due to higher abatement. The strength though not the direction of the effects that result from internalizing the global externality depends on whether countries internalize only the domestic or also the transnational effects from the global pollutant.

Although both types of pollution are caused by capital accumulation in our model, two instruments are required to achieve the first-best solution, for example a tax on local pollution and a tax on the emission of global pollutants. With respect to local pollution, it was shown that optimal taxation requires to set the tax rate equal to the marginal damage to current production. Optimal taxation of the global pollutant, however, also has to take into account that current emissions add to the pollution 
stock and thus cause damages not only to production today but also to production in the future.

The paper also considered asymmetric internalization scenarios, i.e. situations in which the two countries internalize the externalities to different degrees. Without international environmental policy neither country attains the development path it considers to be optimal in this case. We focused on the realistic case that a country that internalizes the global externality strives to implement the global pollution stock it considers to be optimal through international environmental policy. We analyzed two policy options - a subsidy on the reduction of pollution and a subsidy on abatement. It was shown that either policy succeeds in implementing the optimal stock of global pollution. Yet, the global welfare optimum can only be achieved by subsidizing pollution reduction since subsidizing abatement does not correct for the negative externalities from capital accumulation. Consequently, capital accumulation and growth are suboptimally high in the subsidy receiving country.

In our analysis we have assumed perfect information. Although, we shortly pointed to implications of imperfect information, a more detailed analysis of its consequences as well as of strategic incentives arising in the case of international environmental policy are certainly desirable. Also, dropping the simplifying assumption of identical technologies and preferences would allow, for example, to better capture asymmetric internalization in the case of industrialized and developing countries. Integrating these aspects into the present framework might yield further interesting results. 


\section{Appendix}

\subsection{Scenario 2: Derivation of BGP Capital-abatement Ratio}

From the FOCs for $A_{L G}$ and $K,(17)$ and (18), we get

$$
g_{\lambda^{i}}=-(1-\alpha \gamma) Y_{K}^{i}+K_{A}^{i-1}
$$

while combining (17) and (19) gives

$$
g_{\mu^{i}}=\delta \frac{1}{S} P_{G}^{i} Y_{K}^{i}\left(\gamma(1-\alpha) Y_{K}^{i}-K_{A}^{i-1}\right)^{-1}+a .
$$

From differentiating (17) with respect to time, we get a second expression for the dynamics of $g_{\mu^{i}}$

$$
g_{\mu^{i}}=g_{\lambda^{i}}+g_{A_{L G}^{i}}-g_{K}^{i}+\frac{\gamma(1-\alpha) g_{Y}^{i} \frac{Y^{i}}{A_{L G}^{i}}-g_{A_{L G}^{i}}}{\gamma(1-\alpha) \frac{Y^{i}}{A_{L G}^{i}}-1} .
$$

Along the BGP $g_{C}^{i}=g_{Y^{i}}=g_{K^{i}}=g_{a_{F} i}=g_{A_{L G}^{i}}$ again has to hold, such that we get from (52) that along the BGP $g_{\mu^{i}}=g_{\lambda^{i}}+g_{K^{i}}$. Using also $g_{K^{i}}=(1-\alpha \gamma) Y_{K}^{i}-C_{K}^{i}-K_{A}^{i}$ from (5) where we employed (9), we get

$$
g_{\mu^{i}}=-C_{K}^{i}
$$

and from equating (51) and (53)

$$
-\left(C_{K}^{i}+a\right) \frac{S}{\delta P_{G}^{i}}=\left(\gamma(1-\alpha)-K_{A}^{i} Y_{K}^{i-1}\right)^{-1} .
$$

Using (23) gives

$$
K_{A}^{i}=\left(\gamma(1-\alpha)+\frac{\delta a}{C_{K}^{i}+a} \frac{K_{A}^{i}}{K_{A}^{i}+K_{A}^{j}}\right)^{-\frac{1-\alpha \gamma}{1-\gamma}}\left(\frac{p_{L}^{\gamma} S^{\delta}}{b(\alpha \gamma)^{\alpha \gamma}}\right)^{\frac{1}{1-\gamma}} .
$$

Finally, by employing (15) we can now derive the capital-abatement ratio along the BGP to equal (20).

To derive the optimal output-capital ratio rearrange (17) to get

$$
Y_{K}^{i} K_{A}^{i}=(\gamma(1-\alpha))^{-1}\left(\frac{\mu^{i}}{\lambda^{i}}\left(p_{G} \frac{K_{A}^{i}}{A_{L G}^{i}}\right)+1\right) .
$$

Inserting this expression into (54) gives

$$
\frac{\mu^{i}}{\lambda^{i}}\left(p_{G} \frac{K_{A}^{i}}{A_{L G}^{i}}\right)=-\frac{\frac{1}{2} \frac{\delta a}{C_{K}^{i}+a}}{\frac{1}{2} \frac{\delta a}{C_{K}^{i}+a}+\gamma(1-\alpha)}
$$


such that $Y_{K}^{i}$ can be rewritten as

$$
Y_{K}^{i}=\frac{1}{K_{A}^{i}}\left[\frac{1}{\frac{1}{2} \frac{\delta a}{C_{K}^{i}+a}+\gamma(1-\alpha)}\right] .
$$

The BGP growth rate in Scenario 2 can be derived from (8), (17) and (18) to equal

$$
g_{C}^{i}=\frac{1}{\sigma}\left((1-\alpha \gamma) Y_{K}^{i}-\left(K_{A}^{i}\right)^{-1}-\rho\right) .
$$

Using (58) we get (22)

$$
g_{C}^{i}=\frac{1}{\sigma}\left(\frac{(1-\gamma)-\frac{1}{2} \frac{\delta a}{C_{K}^{i}+a}}{\gamma(1-\alpha)+\frac{1}{2} \frac{\delta a}{C_{K}^{i}+a}} \frac{1}{K_{A}^{i}}-\rho\right) .
$$

\subsection{Scenario 2: Derivation of Optimal $\tau_{G}$}

To determine the optimal $\tau_{G}$, first insert $\tau_{L}$ from (32) into (33) which gives

$$
\tau_{G} \frac{P_{G}}{A_{L G}}=1-(1-\alpha) \gamma Y_{K} K_{A} .
$$

From (17) we know that $1-(1-\alpha) \gamma Y_{K} K_{A}=-\frac{\mu}{\lambda} \frac{P_{G}}{A_{L G}}$ has to hold in the optimum. Equating the two expressions shows that the tax rate has to equal the negative ratio of the shadow prices of stock pollution and capital,

$$
\tau_{G}=-\frac{\mu}{\lambda}
$$

Equating the two expressions for $g_{\mu}$ from (19) and (53) gives

$$
-C_{K}=\frac{\delta}{S}\left(\frac{\mu}{\lambda} \frac{1}{A_{L G}}\right)^{-1} Y_{K} K_{A}+a
$$

which reads after some rearranging

$$
-\frac{\mu}{\lambda}=\delta \frac{Y}{S} \frac{1}{C_{K}+a}
$$

Combining (62) and (64) finally gives the optimal tax rate on $P_{G}$ in (35).

\subsection{Derivation of $K_{A}^{f}$ and $g_{C}^{f}$ under $s_{G}$}

Firms in country $f$ that receive a subsidy for pollution reduction will set $K_{A}^{f}$ as follows: Dividing (38) by (39) gives $A_{L}^{f}$ in terms of $A_{L G}^{f}$ :

$$
A_{L}^{f}=\frac{\alpha \gamma}{\gamma(1-\alpha)}\left(1-s_{G} \frac{p_{G} K_{A}^{f}}{A_{L G}^{f}}\right) A_{L G}^{f} .
$$


Dividing (4) by $K$ and inserting (3) as well as (65) gives for the output-capital ratio

$$
Y_{K}^{f}=p_{L}^{-\gamma} S^{-\delta}\left(K_{A}^{f}\right)^{-\gamma}\left[\frac{\alpha \gamma}{\gamma(1-\alpha)}\left(1-s_{G} \frac{p_{G} K_{A}^{f}}{A_{L G}^{f}}\right)\right]^{\alpha \gamma} .
$$

Substituting this expression into (38) and rearranging gives the capital-output ratio chosen by firms under pollution reduction subsidies

$$
K_{A}^{f}=\left(\frac{\gamma(1-\alpha)}{1-s_{G} \frac{p_{G} K_{A}^{f}}{A_{L G}^{f}}}\right)^{-\frac{1-\alpha \gamma}{1-\gamma}}\left(\frac{p_{L}^{\gamma} S^{\delta}}{b(\alpha \gamma)^{\alpha \gamma}}\right)^{\frac{1}{1-\gamma}} .
$$

The optimal subsidy rate (42) can be rewritten by employing $Y^{f}=Y_{K}^{f} P_{G}^{f} \frac{A_{L G}^{f}}{p_{G}}$ and $Y_{K}=\left(1-s_{G} \frac{P_{G}^{f}}{A_{L G}^{f}}\right)\left(\gamma(1-\alpha) K_{A}^{f}\right)^{-1}$ from (38) as

$$
s_{G}=\frac{\delta}{C_{K}^{f}+a} \frac{A_{L G}^{f}}{S}\left(\frac{1-s_{G} \frac{P_{G}^{f}}{A_{L G}^{f}}}{\gamma(1-\alpha)}\right) .
$$

Solving this expression for $s_{G}$ gives

$$
s_{G}=\frac{\delta}{C_{K}^{f}+a} \frac{A_{L G}^{f}}{S}\left(\gamma(1-\alpha)+\frac{\delta}{C_{K}^{f}+a} \frac{P_{G}^{f}}{S}\right)^{-1} .
$$

Substituting this expression into (67), considering that, along the BGP and given (42), $S=2 P_{G}^{f}$ holds and rearranging gives the capital-abatement ratio of Scenario 2, (20).

The growth rate for country $f$ with pollution reduction subsidies can be derived by inserting (40) into (29). Substituting $s_{G} \frac{p_{G}}{A_{L G}^{f}}=\left(-\gamma(1-\alpha) Y_{K}^{f} K_{A}^{f}+1\right)\left(K_{A}^{f}\right)^{-1}$ from (38) gives

$$
g_{C}^{i}=\frac{1}{\sigma}\left((1-\alpha \gamma) Y_{K}^{i}-\frac{1}{K_{A}^{i}}-\rho\right) .
$$

As $K_{A}^{f}$ is equal to (20) this gives the optimal growth rate (22).

\subsection{Derivation of $K_{A}^{f}$ under $s_{A}$}

Dividing (44) by (45) gives

$$
A_{L}^{f}=\frac{\alpha \gamma}{\gamma(1-\alpha)}\left(1-s_{A}\right) A_{L G}^{f}
$$

Proceeding as in Appendix 6.3 gives for the output-capital ratio

$$
Y_{K}^{f}=p_{L}^{-\gamma} S^{-\delta}\left(K_{A}^{f}\right)^{-\gamma}\left(\frac{\alpha \gamma}{\gamma(1-\alpha)}\left(1-s_{A}\right)\right)^{\alpha \gamma}
$$


and equivalently for the output-capital ratio

$$
K_{A}^{f}=\left(\frac{\gamma(1-\alpha)}{1-s_{A}}\right)^{-\frac{1-\alpha \gamma}{1-\gamma}}\left(\frac{p_{L}^{\gamma} S^{\delta}}{b(\alpha \gamma)^{\alpha \gamma}}\right)^{\frac{1}{1-\gamma}} .
$$

The optimal subsidy rate (47) can be rewritten by employing $Y^{f}=Y_{K}^{f} P_{G}^{f} \frac{A_{L G}^{f}}{p_{G}}$ and $Y_{K}=\left(1-s_{A}\right)\left(\gamma(1-\alpha) K_{A}^{f}\right)^{-1}$ from (44) as

$$
s_{A}=\frac{\delta}{C_{K}^{f}+a} \frac{P_{G}^{f}}{S}\left(\frac{1-s_{A}}{\gamma(1-\alpha)}\right) .
$$

Solving this expression for $s_{A}$ gives

$$
s_{A}=\left(\frac{\delta}{C_{K}^{f}+a} \frac{P_{G}^{f}}{S}\right)\left(\gamma(1-\alpha)+\frac{\delta}{C_{K}^{f}+a} \frac{P_{G}^{f}}{S}\right)^{-1} .
$$

Substituting this expression into (73), considering that along the BGP $S=2 P_{G}^{f}$ holds and rearranging gives the capital-abatement ratio of Scenario 2, (20). 


\section{References}

Bahn, O. and Leach, A. (2008), The secondary Benefits of Climate Change Mitigation: an Overlapping Generations Approach, Computational Management Science 5, 233-257.

Barker, T., Johnstone, N. and O'Shea, T. (1993), The CEC Carbon/Energy Tax and Secondary Transport-related Benefits, Energy-Environment-Economy Modelling Discussion Paper No. 5, University of Cambridge, Cambridge.

Bovenberg, A.L. (1999), Green Tax Reforms and the Double Dividend: an Updated Reader's Guide, International Tax and Public Finance 6, 421-443.

Burtraw, D., Krupnick, A., Palmer, K., Paul, A., Toman, M. and Bloyd, C. (2003), Ancillary Benefits of Reduced Air Pollution in the U.S. from Moderate Greenhouse Gas Mitigation Policies in the Electricity Sector, Journal of Environmental Economics and Management 45, 650-673.

Ekins, P. (1996), How Large a Carbon Tax is Justified by the Secondary Benefits of CO2 Abatement?, Resource and Energy Economics 18, 161187.

Elbakidze, L. and McCarl, B.A. (2007), Sequestration Offsets Versus Direct Emission Reductions: Consideration of Environmental Co-Effects, Ecological Economics $60,564-571$.

Eyckmans, J., Bertrand, C. (2000), Integrated Assessment of Carbon and Sulphur Emissions, Simulations with the CLIMNEG Model, ETE Working Paper 200008, Katholieke Universiteit Leuven.

Finus, M. and Rübbelke, D.T.G. (2008), Coalition Formation and the Ancillary Benefits of Climate Policy, Nota di Lavoro 62.2008, Fondazione Eni Enrico Mattei (FEEM), Milano, 2008.

Gielen, D. and Chen, C. (2001), The CO2 Emission Reduction Benefits of Chinese Energy Policies and Environmental Policies: A Case Study for Shanghai, Period 1995-2020, Ecological Economics 39, 257-270.

Grimaud, A. and Rougé, L. (2003), Non-renewable Resources and Growth with Vertical Innovations: Optimum, Equilibrium and Economic Policies, Journal of Environmental Economics and Management 45, 433-453. 
IEA (2007), Energy Security and Climate Policy. Assessing Interactions, OECD/IEA, Paris.

IPCC (1996), Climate Change 1995 - Economic and Social Dimensions of Climate Change, Cambridge University Press, Cambridge.

IPCC (2001), Climate Change 2001 - Mitigation, Cambridge University Press, Cambridge.

Kverndokk, S. and Rosendahl, K. (2000), $\mathrm{CO}_{2}$ Mitigation Costs and Ancillary Benefits in the Nordic Countries the UK and Ireland: A survey, Technical Report Memorandum 34/2000, Department of Economics, University of Oslo.

Li, J.C. (2006), A Multi-Period Analysis of a Carbon Tax Including Local Health Feedback: an Application to Thailand, Environment and Development Economics, 11, 317-342.

Ligthart, J. and van der Ploeg, R. (1994), Sustainable Growth and Renewable Resources in the Global Economy, in Carlo Carraro (ed.), Trade, Innovation, and Environment Dordrecht: Kluwer.

Morgenstern, R.D. (1991), Towards a Comprehensive Approach to Global Climate Change Mitigation, The American Economic Review 81, 140-145.

Pearce, D. (1992), Secondary Benefits of Greenhouse Gas Control, CSERGE Working Paper 92-12, London.

Pearce, D. (2000), Policy Framework for the Ancillary Benefits of Climate Change Policies, in: Ancillary Benefits and Costs of Greenhouse Gas Mitigation, OECD, Paris, 517-560.

Pittel, K. (2002), Sustainability and Endogenous Growth, Cheltenham, UK and Northampton, MA, US: Edward Elgar.

Pittel, K. and Bretschger, L. (2009), The Implications of Heterogeneous Resource Intensities on Technical Change and Growth, CER-ETH Working-Paper 09/120, ETH Zürich. 
Pittel, K. and Rübbelke, D.T.G. (2008), Climate Policy and Ancillary Benefits. A Survey and Integration into the Modelling of International Negotiations on Climate Change, Ecological Economics 68, 210-220.

Plambeck, E.L., Hope, C. and Anderson, J. (1997), The Page 95 Model: Integrating the Science and Economics of Global Warming, Energy Economics 19, 77-101.

Porter, M. (1991), America's Green Strategy, Scientific American 264, 96.

Rebelo, S.T. (1991), Long-Run Policy Analysis and Long-Run Growth, Journal of Political Economy 99, 500-521.

Rübbelke, D.T.G. (2002), International Climate Policy to Combat Global Warming - An Analysis of the Ancillary Benefits of Reducing Carbon Emissions, New Horizons in Environmental Economics, Cheltenham, UK; Northampton, MA: Edward Elgar.

Schou, P. (2000), Polluting Non-Renewable Resources and Growth, Environmental and Resource Economics 16, 211227.

Schou, P. (2002), When Environmental Policy is Superfluous: Growth and Polluting Resources, Scandinavian Journal of Economics 104, 605-620.

Smulders, S. and Gradus, R. (1996), Pollution Abatement and Long-Term Growth, European Journal of Political Economy 12, 505-532.

Tol, R. (2002), Estimates of the Damage Costs of Climate Change, Part II. Dynamic Estimates, Environmental and Resource Economics 21, 135160.

Withagen, C. (1995), Pollution, Abatement and Balanced Growth, Environmental and Resource Economics 5, 1-8. 


\title{
BC3 WORKING PAPER SERIES
}

\author{
Basque Centre for Climate Change (BC3), Bilbao, Spain
}

The BC3 Working Paper Series is available on the internet at the following addresses:

http://www.bc3research.org/lits_publications.html

$\underline{\text { http://ideas.repec.org/s/bcc/wpaper.html }}$

BC3 Working Papers available (see website for full list):

2010-01

Sara L. M. Trærup, Ramon Arigoni Ortiz and Anil Markandya: The Health Impacts of Climate Change: A Study of Cholera in Tanzania

2010-02

Mikel González-Eguino, Ibon Galarraga and Alberto Ansuategi: Carbon leakage and the Future of Old Industrial Regions after Copenhagen

2010-03

Roger Fouquet: Divergences in the Long Run Trends in the Price of Energy and of Energy Services

2010-04

Giacomo Giannoccaro and Julia Martin-Ortega: Environmental Concerns in Water Pricing Policy: an Application of Data Envelopment Analysis (DEA)

2010-05

Roger Fouquet: The Slow Search for Solutions: Lessons from Historical Energy Transitions by Sector and Service

Ibon Galarraga, Mikel González-Eguino and Anil Markandya: Evaluating the Role of Energy Efficiency Labels: the Case of Dish Washers

Luis M. Abadie, Mikel González-Eguino and José M. Chamorro: Optimal Abandonment of Coal-Fired Stations in the EU

2010-08

Dirk Rübbelke and Stefan Vögele: Impacts of Climate Change on European Critical Infrastructures: The Case of the Power Sector

Roger Fouquet: The Sustainability of 'Sustainable' Energy Use: Historical Evidence on the Relationship between Economic Growth and Renewable Energy

Karen Pittel and Dirk Rübbelke: Energy Supply and the Sustainability of Endogenous Growth

Ramon Arigoni Ortiz, Alexander Golub, Oleg Lugovoy, Anil Markandya and James Wang: The DICER Model: MethodologicalIissues and Iinitial Results.

Elena Ojea, Julia Martin-Ortega and Aline Chiabai: Classifying Ecosystem Services for Economic Valuation: the Case of Forest Water Services

2010-13

Aline Chiabai, Chiara Travisi, Anil Markandya, Helen Ding, and Paulo Nunes: Economic Assessment of Forest Ecosystem Services Losses: Cost of Policy Inaction

2010-14

Kaysara Khatun: Competing Ecosystem services: an Assessment of Carbon and Timber in the Tropical forests of Central America 